\title{
APLIKASI MSC PATRAN UNTUK PENENTUAN RENTANG MAKSIMUM PENYANGGA PIPA PRIMER REAKTOR AP1000
}

\author{
Elfrida Saragi, Abdul Hafid, Geni Rina S \\ Pusat Teknologi dan Keselamatan Reaktor Nuklir (PTKRN) - BATAN \\ Kawasan Puspiptek Serpong, Gedung 80, Tangerang Selatan, Banten \\ Telp/Fax:021-7560912/ 021-7560913, Email: frida@batan.go.id
}

\begin{tabular}{|c|c|c|}
\hline Diterima & Diterima dalam bentuk revisi & Disetujui \\
\hline 15 Januari 2015 & 20 April 2015 & 04 Mei 2015 \\
\hline
\end{tabular}

\begin{abstract}
ABSTRAK
APLIKASI MSC PATRAN UNTUK PENENTUAN RENTANG MAKSIMUM PENYANGGA PIPA PRIMER REAKTOR AP1000. Penyangga pipa digunakan antara lain untuk menjaga agar pipa tidak membebani komponen dan mencegah terjadinya lendutan yang berlebihan. Penentuan posisi penyangga pipa ditetapkan oleh beberapa faktor, seperti adanya katup, adanya belokan pipa dan jarak antara dua komponen utama reaktor yaitu tangki reaktor dan pembangkit uap. Untuk transpor panas dari tangki reaktor ke pembangkit uap digunakan pipa hot leg. Tujuan penelitian ini adalah untuk dapat menentukan batas jarak penyangga yang baik dan sudut belok pipa pada pipa primer reaktor daya AP1000 berdiameter 37,5 inchi diameter luar dan 31 inchi diameter dalam. Metode analisis yang digunakan adalah metode komputasi dengan pemodelan menggunakan software MSC Patran. Hasil perhitungan menunjukkan bahwa semakin jauh jarak penyangga pipa maka besar lendutan yang terjadi makin besar. Nilai maksimal yang cukup baik dan sesuai standar ASME adalah pada jarak $5 \mathrm{~m}$ dengan sudut belok pipa 45 derajat. Pada jarak tersebut defleksi maksimum yang terjadi sebesar $1.76 \mathrm{~cm}$ dan tegangan tekuk sebesar $2.06 \mathrm{MPa}$.
\end{abstract}

Kata kunci: Tegangan tekuk, Defleksi, Penyangga pipa, Hotleg reaktor AP1000.

\begin{abstract}
APPLICATION OF MSC-PATRAN TO DETERMINE THE MAXIMUM RANGE SUPPORT OF PRIMARY PIPES NUCLEAR REACTOR AP100. Pipe supports used among others, to keep the pipes from overloding the components and prevent excessive deflection. The position of the pipe support is determined by several factors, such as the presence of valves, pipe bends and the distance between the two main components of reactor. Heat transport from reactor tank to the steam generator are performed using hotleg pipe. The purpose of this study was to determine a safe support distance limit and the angle of the pipe turn and bending on the primary pipe of AP1000 power reactor with the outer pipe diameter of 37.5 inches, and the inner diameter of the pipe is 31 inches. The analytical method used is the computational modeling methods using the MSC Patran software. The calculation results show that the greater the distance of the pipe support, then deflection occurs is greater. The maximum value that is quite good, and in accord to ASME standards is at a distance of 5 meter and the angle of pipe turn is 45 degree. At that distance, the maximum deflection occurs is $1.76 \mathrm{~cm}$ and bending stress is $2.06 \mathrm{MPa}$.
\end{abstract}

Keywords: Deflection, Bending stress, Support pipes, Hotleg reactor AP1000. 


\section{PENDAHULUAN}

Pipa pada instalasi reaktor nuklir digunakan untuk mengalirkan fluida yang berfungsi sebagai sarana transpor panas. Pipa yang dialiri fluida akan memerlukan penyangga agar senantiasa kokoh. Penyangga pipa digunakan karena berbagai macam alasan, antara lain adalah untuk meningkatkan kemampuan pipa dengan penempatan penyangga di beberapa tempat dan untuk mencegah terjadinya lendutan (bending) berlebihan yang dapat menyebabkan konsentrasi tegangan tekuk ditengah pipa antara dua penyangga pipa ${ }^{[1]}$. Penyangga adalah alat yang digunakan untuk menahan atau memegang sistem perpipaan dan dirancang untuk dapat menahan berbagai macam bentuk pembebanan baik statis maupun dinamis. Penempatan penyangga harus memperhatikan pergerakan sistem perpipaan terhadap profil pembebanan yang mungkin terjadi pada berbagai kondisi. Berdasarkan pembebanannya penyangga pipa dapat dibagi menjadi dua yaitu pembebanan statis dan pembebanan dinamis. Penyangga harus mampu menahan keseluruhan berat sistem perpipaan, termasuk didalamnya berat pipa, berat insulasi, berat fluida dan berat katup. Penyangga pipa dapat terbuat dari logam paduan dengan berbagai kelengkapannya yang dipilih dan ditetapkan sesuai dengan jenis fluida yang mengalir di dalam pipa. Posisi penyangga ditentukan oleh beberapa faktor antara lain adanya katup, tata letak pipa, belokan pipa dan rentang jarak yang terlalu jauh. Pada makalah ini akan dibahas cara untuk menentukan jarak maksimum antara dua penyangga pipa sebagai bahan pertimbangan dalam menentukan batas rentang jarak terjauh pada pipa dan sudut belokan pipa. Sebagai data input akan digunakan data diameter dan jenis material yang digunakan pada pipa hot leg reaktor daya AP1000.

Peletakan penyangga pipa lurus panjang yang terlalu jauh akan dapat mengakibatkan terjadinya tekukan atau lendutan pada tengah pipa yang melebihi batas standar yang diizinkan. Akan tetapi terlalu banyak penyangga juga kurang baik karena selain tidak ekonomis juga dapat mengurangi fleksibilitas pipa. Oleh karena itu tujuan penelitian ini adalah untuk dapat menentukan batas jarak penyangga yang baik menggunakan pipa primer reaktor daya AP1000 sebagai bahan rujukan. Pipa hotleg memiliki diameter luar pipa 37,5 inchi dan diameter dalam 31 inchi ${ }^{[2,3,4]}$. Pipa hot leg berisi fluida berupa air bertekanan. Metode yang digunakan adalah metode komputasi dengan pemodelan, perhitungan dan analisis dilakukan dengan software MSC Patran. Secara perhitungan analitik sulit dilakukan karena merupakan perhitungan statis tak tentu dimana kedua ujung pipa merupakan tumpuan jepit yaitu transilasi dan rotasi kearah $X, Y, Z$ adalah nol $\left(T_{x}, T_{y}, T_{z}=0\right.$ dan $R_{x}, R_{y}, R_{z}$ $=0)$. Pipa hotleg adalah pipa yang digunakan untuk menghubungkan tangki reaktor bertekanan (reactor pressure vessel) dengan pembangkit uap (steam generator) dan berfungsi sebagai sarana transpor panas dari tangki reaktor bertekanan ke unit pembangkit uap.

Analisis dilakukan dengan mengambil sampel pipa searah dengan sumbu $\mathrm{x}$ atau sejajar dengan sumbu pipa dan pada belokan pipa. Untuk dapat memperoleh hasil analisis maka dibuat empat model pipa yang berdiameter sama dan berisi fluida yang sama tetapi dengan panjang dan sudut yang berbeda. Oleh karena batasan analisis yang dilakukan adalah penentuan rentang jarak antara dua penyangga pipa maka peletakan penyangga adalah pada ujung-ujung pipa dan pada belokan pipa. Material pipa hot leg yang digunakan oleh reaktor daya AP1000 adalah material SA376-TP316LN[5]. 


\section{TEORI}

Penyangga pipa (supporting pipe) adalah suatu komponen yang didesain dan digunakan untuk memindahkan dan meneruskan beban dari pipa ke struktur penyangga. Dalam operasi normalnya sistem perpipaan menerima beban yang banyak dan kompleks. Dalam hal ini beban pipa yang diterima adalah beban sustain. Beban sustain adalah beban yang dialami oleh instalasi sistem perpipaan terus menerus. Beban sustain yang terdiri dari beban statis dan beban berubah seperti yang ditunjukkan pada Gambar 1.

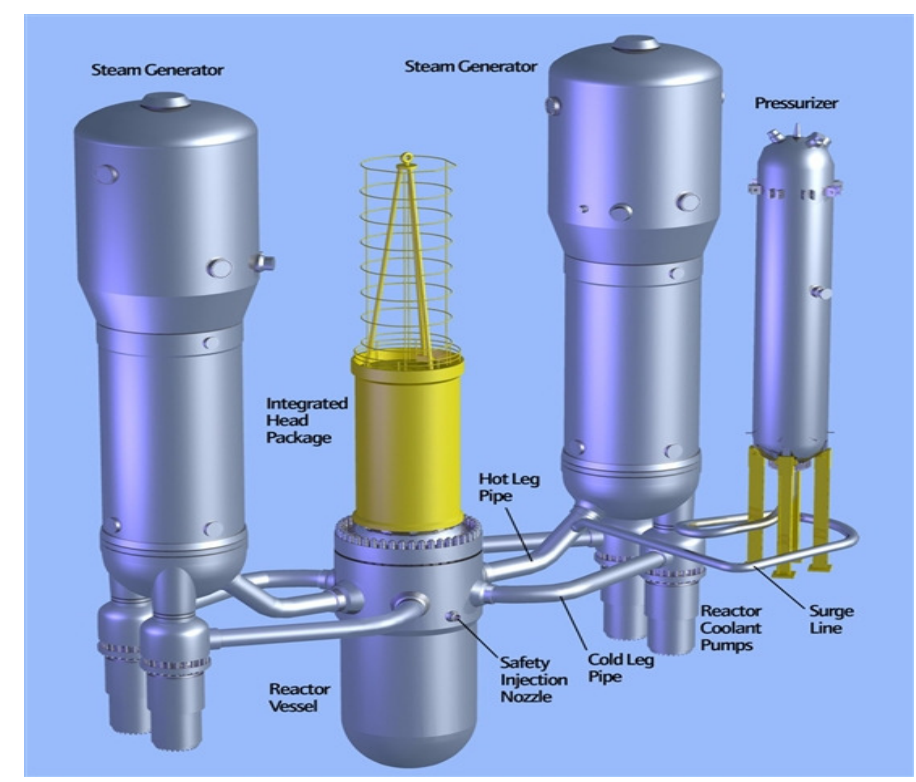

Gambar 1. Hotleg Reaktor AP100 ${ }^{[2,3,6,7]}$.

Yang meliputi berat komponen sistem perpipaan, berat isolasi, dan berat struktur sistem perpipaan itu sendiri dan beban berubah yang meliputi berat fluida yang mengalir di dalam sistem perpipaan atau fluida lain yang digunakan untuk pengujian sistem perpipaan tersebut.

Fungsi utama dari penyangga pipa antara lain adalah sebagai penyerap beban kejut, pengarah kerataan permukaan pipa, penyangga beban yang diletakkan di atas pipa, dan sebagainya. Pada makalah ini beban yang akan digunakan adalah beban sustain dari pipa. Beban sustain merupakan jumlah total berat pipa dengan berat fluida. Untuk memperoleh berat pipa yang digunakan maka nilai-nilai diameter dalam dan luar pipa serta berat jenis material pipa harus diketahui. Sehingga berat material pipa (Beban statis) dapat dihitung dengan persamaan $(1):[1,8]$

$$
W_{\text {pipa }}=\frac{\pi\left(D_{o}^{2}-D_{i}^{2}\right)}{4}\left(\rho_{\text {pipa }}\right)
$$

Dimana $W_{\text {pipa }}$ adalah berat pipa, $\pi$ adalah konstanta untuk menghitung luas lingkaran, $D_{o}$ adalah diameter luar pipa, $D_{i}$ adalah diameter dalam pipa dan $\rho_{\text {pipa }}$ berat jenis material pipa.

Setelah memperoleh berat pipa, selanjutnya dilakukan perhitungan berat fluida yang mengisi pipa secara penuh. Untuk menghitung berat fluida di dalam pipa dapat dilakukan dengan persamaan (2). Sehingga pada akhirnya beban total pipa dapat dihitung dengan persamaan (3). 


$$
\begin{aligned}
& W_{\text {pipa }}=\frac{\pi D_{i}^{2}}{4}\left(\rho_{\text {fluida }}\right) \\
& W_{\text {total }}=W_{\text {pipa }}+W_{\text {fluida }}
\end{aligned}
$$

Beban yang bekerja pada pipa akan mengakibatkan defleksi (lendutan). Analisa yang digunakan adalah analisis tegangan tekuk. Tegangan tekuk adalah tegangan yang ditimbulkan oleh momen (M) yang bekerja diujung-ujung pipa sehingga tegangan ( stress ) yang terjadi tidak melebihi batas besaran maksimal tegangan yang diatur oleh Standard code Internasional yaitu ASME SA-312[5]. Tegangan tekuk maksimum pada permukaan pipa dan nol pada sumbu pipa, karena tegangan tersebut merupakan fungsi jarak dari sumbu ke permukaan pipa. Analisa tegangan pipa dilakukan dengan pendekatan metode elemen hingga. Besar tegangan tekuk maksimum $\left(\sigma_{\text {Tekuk } k_{\max }}\right)$ dan tegangan geser maksimum $\left(\tau_{\max }\right)$ yang ditunjukkan pada persamaan (4) dan persamaan (5) ${ }^{[9]}$.

$$
\begin{aligned}
& \sigma_{\text {Tekuk }_{-} \max }=\frac{M c}{I} \\
& \tau_{\max }=\frac{V h^{2}}{8 I}
\end{aligned}
$$

Dimana :

$\mathrm{I}=$ momen inersia penampang beam $=(1 / 12)^{*} b^{*} h^{3}$

$\mathrm{c}=$ jarak antara momen yang terjadi dengan gaya geser

$\mathrm{b}=$ tebal pipa $(\mathrm{m})$

$\mathrm{h}=$ tinggi pipa $(\mathrm{m})$

$\mathrm{V}=$ gaya geser

Defleksi maksimum yang terjadi antara penyangga pipa merupakan deformasi maksimum $(\varepsilon)$ dan tegangan termal $\left(\sigma_{\text {termal }}\right)$ ditunjukkan pada persamaan (7) dan persamaan $(8)^{[1,9] \text {; }}$

$$
\begin{aligned}
& \varepsilon=(1+\mu) \alpha \Delta T \\
& \sigma_{\text {termal }}=D\left(\varepsilon-\varepsilon_{0}\right)
\end{aligned}
$$

dimana:

$\mathrm{D}=$ matriks sifat material

$\alpha=$ koefisien ekspansi panas

$\mathrm{T}=$ temperatur

$\mathrm{L}=$ panjang pipa (meter)

$\mathrm{E}=$ modulus elastisitas $(\mathrm{MPa})$

\section{METODOLOGI}

\subsection{Sistem perpipaan}

Untuk pembuatan model maka diperlukan acuan berupa standar dan kode. Untuk instalasi nuklir, kode dan standar yang digunakan untuk sistem perpipaan mengacu pada ASME kode Komponen Bagian III kelas 1, Aturan untuk kontruksi komponen fasilitas nuklir[10]. Untuk material pipa yang digunakan adalah SA376-TP316LN dengan tegangan maksimumnya yang diizinkan sebesar $132 \mathrm{MPa}^{[5,10]}$. 


\subsection{Data Pemodelan}

Untuk simulasi dibutuhkan data- data inputan seperti data geometri pipa dan spesisifikasi teknis ditunjukkan pada tabel 1 .

Tabel 1. Geometri pipa dan spesifikasi teknis ${ }^{[3,6,7,11]}$.

\begin{tabular}{|c|c|}
\hline $\begin{array}{l}\text { Diameter luar pipa } \\
\text { Diameter dalam pipa }\end{array}$ & $\begin{array}{l}37.5 \text { inchi } \\
31 \text { inchi }\end{array}$ \\
\hline \multicolumn{2}{|l|}{ Spesifikasi Teknis } \\
\hline 1. Spesifikas & \\
\hline Material Pipa & SA376-TP316LN \\
\hline Modulus Elastisitas & $193 \mathrm{GPa}$ \\
\hline Massa Jenis & $8000 \mathrm{Kg} / \mathrm{m}^{3}$ \\
\hline Poisson ratio & 0.3 \\
\hline Koefisian termal ekspansi $(\alpha)$ pada suhu $343^{\circ} \mathrm{C}$ & $1,78 \times 10^{-5}\left(\mathrm{~m} / \mathrm{m} /{ }^{0} \mathrm{C}\right)$ \\
\hline \multicolumn{2}{|c|}{ 2. Spesifikasi Fluida } \\
\hline Fluida & Air \\
\hline Temperatur fluida & $321 \circ \mathrm{C}$ \\
\hline $\begin{array}{l}\text { Massa jenis air pada tekanan } 16,5 \mathrm{MPa} \text { dan } \\
\text { temperatur } 316^{\circ} \mathrm{C}\end{array}$ & $664,7 \mathrm{~kg} / \mathrm{m}^{3}$ \\
\hline
\end{tabular}

\subsection{Proses Pemodelan}

Pemodelan menggunakan perangkat lunak MSC Patran ${ }^{[12]}$ berbasis metode elemen hingga membutuhkan inputan data geometri seperti ukuran diameter pipa, jarak antara rentang penyangga dan sudut belokan pipa. Setelah gambar terbentuk maka dilakukan diskritisasi yaitu membagi bidang atau panjang dengan beberapa bagian dan kemudian memberikan data sifat material dan data sifat elemen ditunjukkan pada Gambar 2.

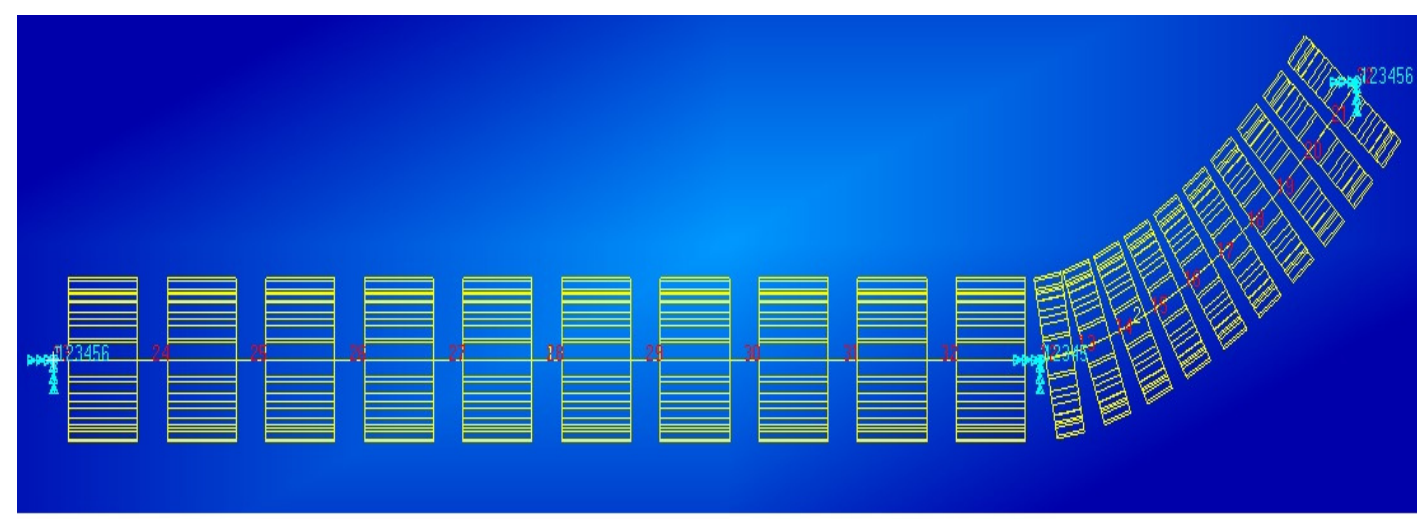

Gambar 2. Model geometri dengan sudut belokan pipa 45 derajat.

Setelah seluruh input data geometri dan sifat material selesai maka dilakukan pemberian beban. Beban yang diberikan adalah beban berat, temperatur fluida dan momen inersia penampang beam. Beban berat dan momen inersia diperoleh dengan melakukan perhitungan menggunakan persamaan 1,2,3 dan persamaan 6 yang disajikan dalam bentuk tabel 2. 
Tabel 2. Hasil perhitungan untuk Beban.

\begin{tabular}{lr}
\hline Berat terdistribusi pipa persatuan panjang $(\mathrm{Kg} / \mathrm{m})$ & 1810,742 \\
\hline Berat terdistribusi fluida persatuan panjang $(\mathrm{Kg} / \mathrm{m})$ & 486,699 \\
\hline Total berat $\left(\mathrm{W}_{\mathrm{t}}\right)=\mathrm{W}_{\text {pipa }}+\mathrm{W}_{\text {fluida }}(\mathrm{N} / \mathrm{m})$ & 22537,89599 \\
\hline Momen inersia penampang beam $\left(\mathrm{m}^{4}\right)$ & 0,021535 \\
\hline
\end{tabular}

Pemberian beban dilakukan sepanjang permukaan pipa berupa total berat, momen inersia penampang beam, temperatur fluida. Kemudian diberikan tumpuan jepit berupa tegangan jepit dimana pada ujung pipa dilakukan translasi dan rotasi kearah $X, Y, Z$ sebesar nol dan pada posisi belokan diberikan translasi kearah $Y=0$ yang ditunjukkan pada Gambar 3.

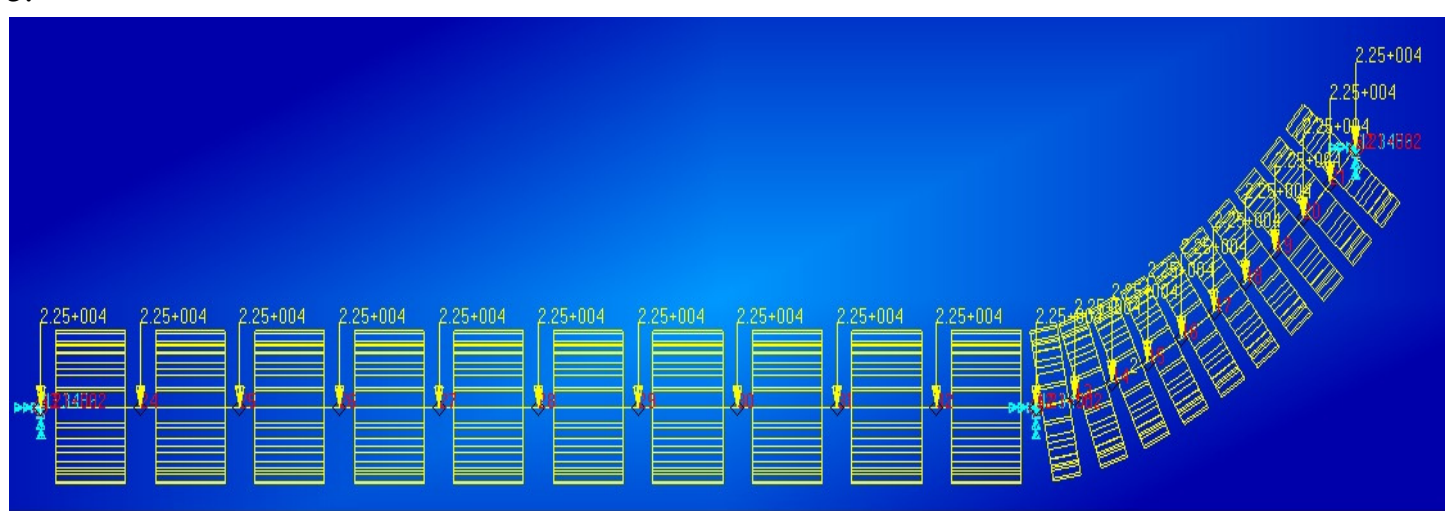

Gambar 3. Model geometri yang telah diberikan beban.

Setelah semua input data diberikan maka langkah selanjutnya adalah menganalisis sehingga dapat diperoleh hasil analisis berupa defleksi maksimum untuk berbagai jarak rentang pipa lurus dan sudut belokan pipa.

\section{HASIL DAN PEMBAHASAN}

Berdasarkan hasil analisis menggunakan perangkat lunak MSC-Patran diperoleh bahwa hasil simulasi berupa defleksi/lendutan yang digunakan untuk menentukan batas jarak penyangga yang baik menggunakan sampel pipa primer reaktor AP1000 dengan tipe material SA376-TP316LN pada berbagai jarak antara dua penyangga pipa dan sudut belokan pipa ditunjukkan pada Gambar 4, 5, 6 dan 7 dibawah ini. Pada Gambar 4, model 1 dengan jarak antara 2 penyangga pipa lurus sebesar 4 meter dengan sudut belokan 45 derajat dan input beban yang diberikan adalah total berat sebesar 22537,89599 N/m, temperatur fluida sebesar $321^{\circ} \mathrm{C}$, momen inersia penampang beam sebesar $0.021535 \mathrm{~m}^{4}$ dan tekanan sebesar $16.5 \mathrm{MPa}$ maka defleksi yang dihasilkan sebesar $0.341 \mathrm{~cm}$ dan tegangan tekuk sebesar $369 \mathrm{MPa}$. 


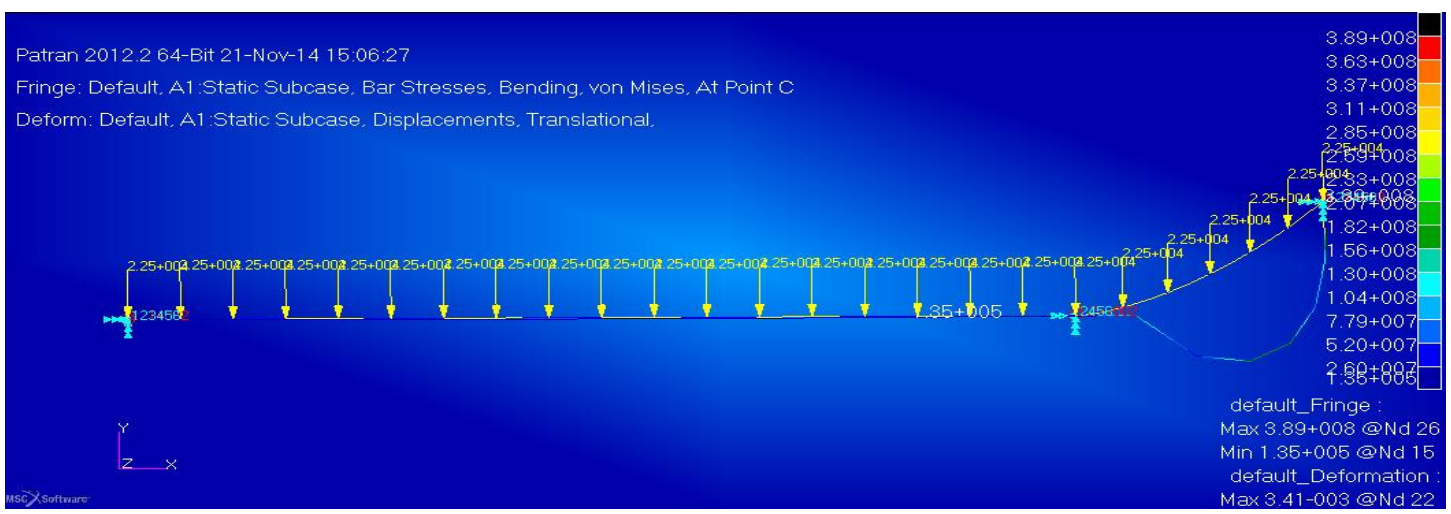

Gambar 4. Defleksi pada pipa lurus 4 meter dengan sudut belok pipa $45^{\circ}$.

Pada Gambar 5, model 2 dengan jarak antara 2 penyangga pipa lurus sebesar 5 meter dengan sudut belokan 45 derajat dan input beban yang diberikan sama dengan pada Gambar 4 maka defleksi maksimum yang dihasilkan sebesar $1.76 \mathrm{~cm}$ dan tegangan tekuk sebesar $2.06 \mathrm{MPa}$.

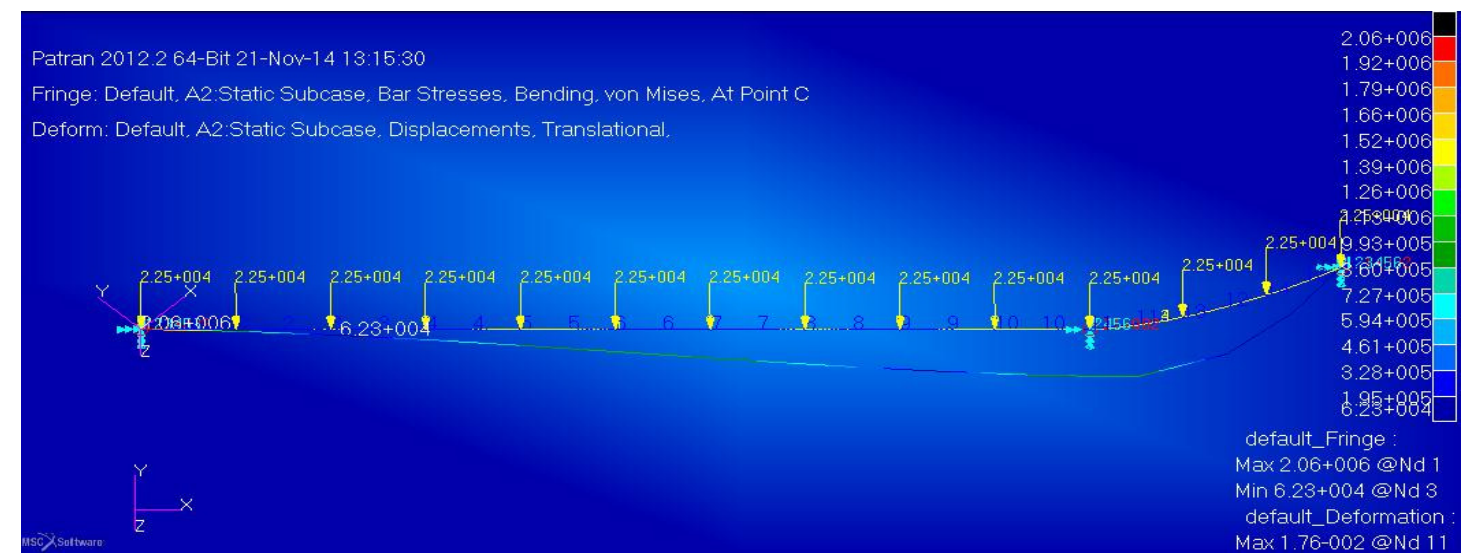

Gambar 5. Defleksi pada pipa lurus 5 meter dengan sudut belok pipa $45^{\circ}$.

Selanjutnya, model 3 pada Gambar 6 untuk jarak rentang penyangga pipa lurus 5.2368 dengan sudut belokan 45 derajat maka defleksi maksimum diperoleh sebesar 0.404 $\mathrm{cm}$ dan tegangan tekuk sebesar $432 \mathrm{MPa}$.

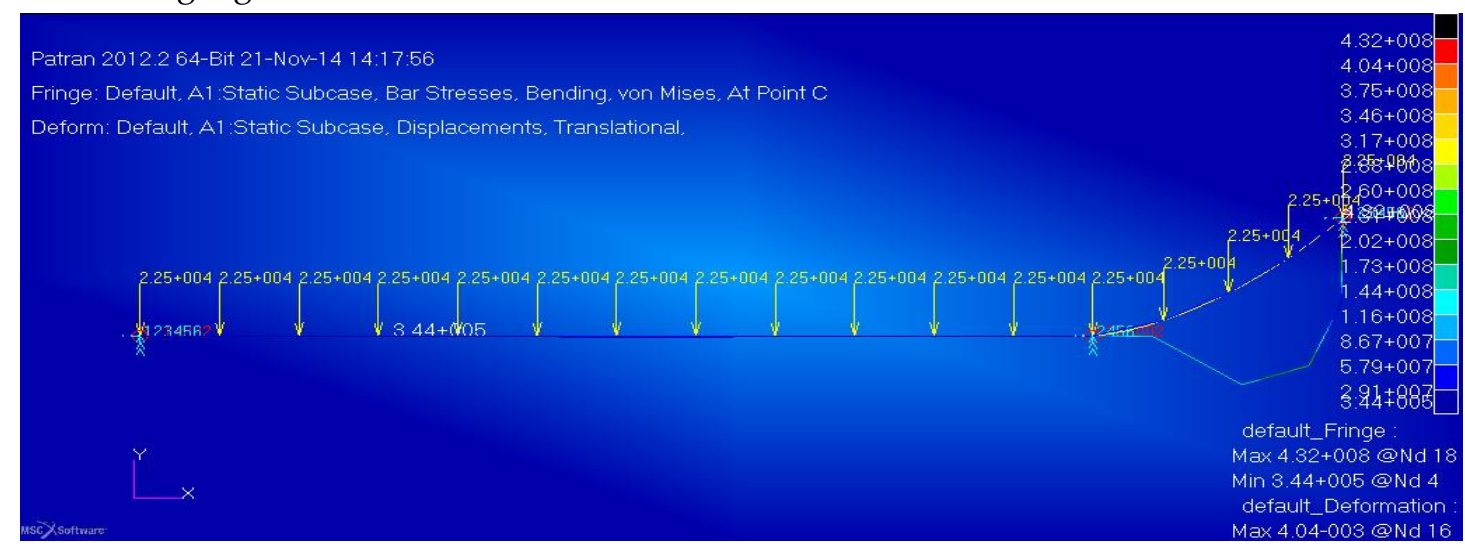

Gambar 6. Defleksi pada pipa lurus 5.2368 meter dengan sudut belok pipa $45^{\circ}$. 
Pada Gambar 7, model 4 untuk jarak rentang pipa lurus 5 meter dengan sudut belokan 51 derajat dan perlakukan yang dilakukan sama dengan pada Gambar 4 maka hasil simulasi diperoleh adalah defleksi maksimum sebesar 0.593 meter dan tegangan tekuk sebesar $594 \mathrm{MPa}$.

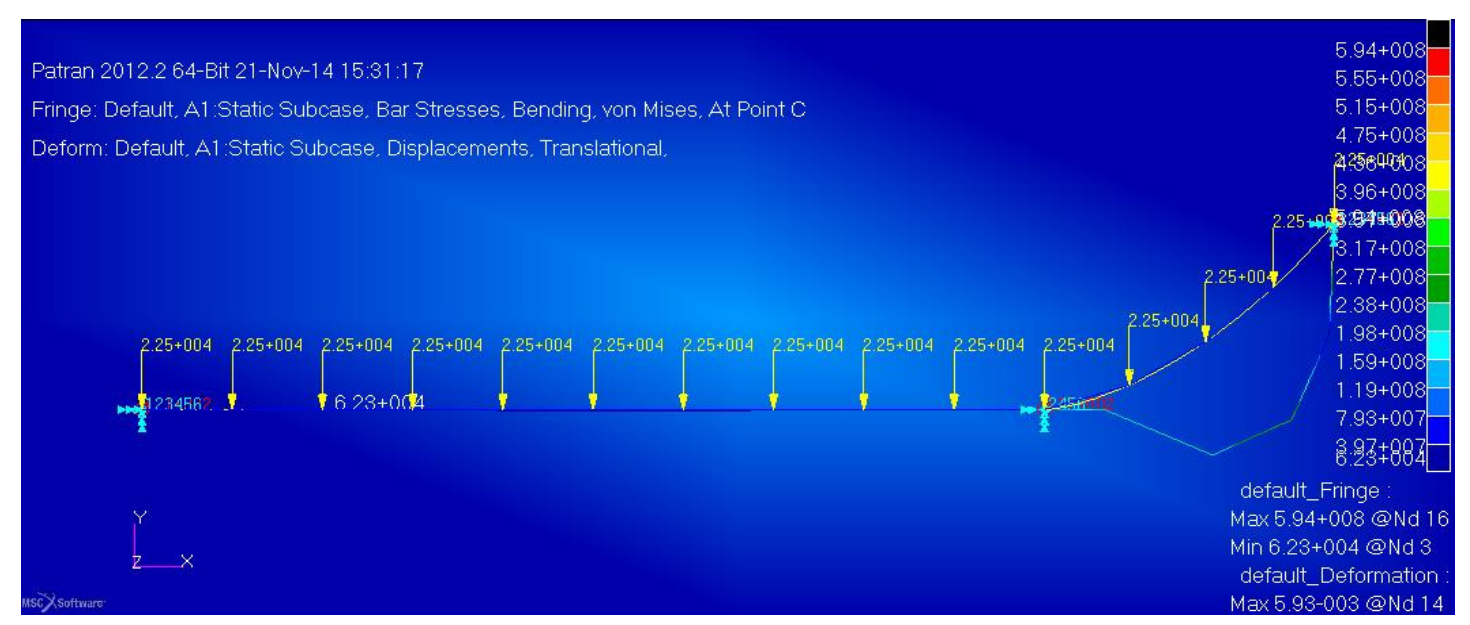

Gambar 7. Defleksi pada pipa lurus 5 meter dengan sudut belok pipa $51^{0}$.

Pada Gambar 8 untuk jarak pipa lurus 5 meter dengan sudut belokan 45 derajat, dimana fluida didalam pipa dianggap pada suhu kamar dan diberikan beban yang sama dengan Gambar 4 maka defleksi maksimum yang dihasilkan sebesar 3.42E-005 cm dan tegangan tekuk sebesar $2.06 \mathrm{MPa}$.

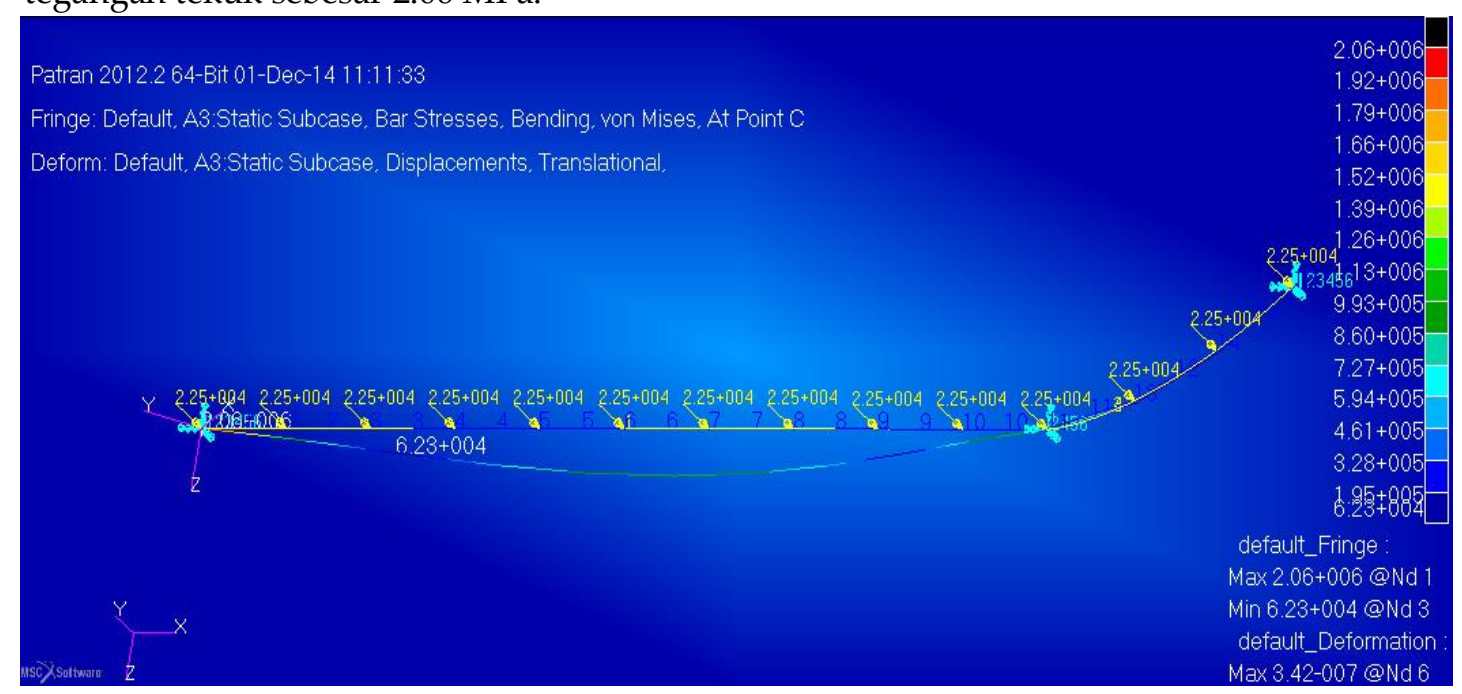

Gambar 8. Defleksi pada pipa 5 meter dengan sudut belok pipa $45^{\circ}$ dan $\mathrm{T}=30^{\circ} \mathrm{C}$.

Gambar diatas menunjukkan bahwa jarak antar penyangga pipa lurus panjang yang terlalu jauh maupun pendek dapat mengakibatkan terjadinya tegangan tekuk yang besar dan melebihi batas ketentuan persyaratan nuklir yang ada pada ASME section III. Besar tegangan tekuk yang dizinkan untuk persyaratan nuklir adalah $1 / 4$ dari tegangan maksimum yaitu sebesar $33 \mathrm{MPa}$. Hasil simulasi menggunakan MSC Patran yaitu berupa defleksi maksimum dan tegangan tekuk yang ditunjukkan pada tabel 3. 
Tabel 3.1. Hasil Simulasi berupa defleksi maksimum dengan suhu fluida $321{ }^{\circ} \mathrm{C}$.

\begin{tabular}{cccccc}
\hline \multirow{2}{*}{$\begin{array}{c}\text { Jarak support } \\
(\text { meter })\end{array}$} & $\begin{array}{c}\text { Sudut belok } \\
\text { Pipa }( \\
\text { derajat) }\end{array}$ & \multicolumn{4}{c}{ Defleksi maksimum (meter) } \\
\cline { 3 - 6 } & 45 & Magnitude & $\mathrm{X}$ & $\mathrm{Y}$ & $\mathrm{Z}$ \\
\hline 4.0 & 45 & $1.71 \mathrm{E}-03$ & $2.33 \mathrm{E}-03$ & $-2.51 \mathrm{E}-03$ & 0 \\
5.0 & 45 & $4.04 \mathrm{E}-03$ & $6.993 \mathrm{E}-03$ & $-3.42 \mathrm{E}-07$ & $1.61 \mathrm{E}-02$ \\
5.2368 & 51 & $5.93 \mathrm{E}-03$ & $4.27 \mathrm{E}-03$ & $-3.0 \mathrm{E}-03$ & 0 \\
5.0 & 51 & & & $-4.12 \mathrm{E}-03$ & 0 \\
\hline
\end{tabular}

Tabel 3.2. Hasil Simulasi berupa tegangan tekuk dengan suhu fluida $321^{\circ} \mathrm{C}$.

\begin{tabular}{cccccc}
\hline Jarak support & Sudut belok & \multicolumn{4}{c}{ Tegangan Tekuk (MPa) } \\
\cline { 3 - 6 } (meter) & Pipa ( derajat) & Von Mises & X & Y & $\mathrm{Z}$ \\
\hline 4.0 & 45 & 389 & 175 & 0 & 0 \\
5.0 & 45 & 2.06 & 1.06 & 0 & 0 \\
5.2368 & 45 & 432 & 220 & 0 & 0 \\
5.0 & 51 & 594 & 302 & 0 & 0 \\
\hline
\end{tabular}

Tabel 3.3. Hasil Simulasi pada posisi support 5 meter dengan suhu fluida $30{ }^{\circ} \mathrm{C}$.

\begin{tabular}{cccc}
\hline $\begin{array}{c}\text { Sudut belok pipa } \\
\text { (derajat) }\end{array}$ & \multicolumn{2}{c}{$\begin{array}{c}\text { Defleksi maksimum } \\
\text { (meter) }\end{array}$} & $\begin{array}{c}\text { Tegangan tekuk } \\
\text { (MPa) }\end{array}$ \\
\hline & Magnitude/ von mises & $3.42 \mathrm{E}-07$ & 2.06 \\
45 & $\mathrm{X}$ & 0 & 1.06 \\
& $\mathrm{Y}$ & $-3.42 \mathrm{E}-07$ & 0 \\
$\mathrm{Z}$ & 0 & 0 \\
\hline
\end{tabular}

\section{KESIMPULAN}

Dari hasil analisis simulasi menggunakan metode tegangan tekuk maksimum maka jarak rentang penyangga yang sesuai standar ASME adalah pada jarak 5 meter dengan sudut belokan pipa sebesar 45 derajat. Pada jarak tersebut defleksi maksimum yang terjadi sebesar $1.76 \mathrm{~cm}$ dan tegangan tekuk sebesar $2.06 \mathrm{MPa}$. Jarak antar penyangga pipa lurus yang terlalu jauh maupun pendek dengan sudut belokan pipa 45 derajat atau 51 derajat akan dapat mengakibatkan terjadinya tegangan tekuk yang besar pada belokan pipa dan besar tegangan tekuknya melebihi batas ketentuan persyaratan nuklir yang ada. Tegangan tekuk yang diizinkan pada code ASME Section III adalah maksimal sebesar 1/4 dari tegangan maksimum material pipa SA376-TP316LN yaitu sebesar $33 \mathrm{MPa}$. Besar defleksi maksimum dipengaruhi oleh temperatur fluida yang mengalir di dalam pipa.

\section{UCAPAN TERIMAKASIH}

Penulis menyampaikan terimakasih kepada PT Emtres Indonesia yaitu Bapak Didi Budhyarso dan Bapak Fajar yang telah memberikan pengetahuan tentang perangkat lunak MSC-Patran.

\section{DAFTAR PUSTAKA}

[1]. CROCKER, SABIN, Piping Handhook, 7th edition,McGraw Hill,New York, 2011.

[2]. TERRY L. SCHULZ, "AP1000 Nuclear Power Plant", Consulting Engineer, Westinghouse Electric Company, LLC (412) 374-5120, JULY 22, 2008.

[3]. Anonimous, "The Westinghouse AP1000 Advanced Nuclear Plant", Westinghouse Electric Co.,LLC, 2003. 
[4]. J.W. WINTERS, J. A. CLELLAND, AP1000 Design And Construction Integration, ICAPP'04-4254, June 2004

[5]. Particular Material " Grade TP316 according to ASME SA-312",Welker Engineering Company, Stockholm, 2004-10-22.

[6]. Anonimous, "Westinghouse AP1000 ${ }^{\mathrm{TM}}$ Nuclear Power Plant", Information Submission to VINATOM, Westinghouse Non-Proprietary Class 3, Vietnam, p.8, 2009.

[7]. J. A. GREEN and G. S. ANDERSON (Originator), "AP1000 Pre-Construction Safety Report, Coolant System and Connected Systems Design Control Document", Westinghouse, UK, Page 5.1-10 to 5.1-15, 2009.

[8]. D.P. VAKHARIA, MOHD. FAROOQ. A, “Determination of Maximum Span Between Pipe Supports Using Maximum Bending Stress Theory", International Journal of Recent Trends in Engineering, Vol. 1 No 6, Academy Publisher , 2009.

[9]. FRANK L. STASA, "Applied Finite Element Analysis For Engineers", Florida Institute of Technology , 1985.

[10]. ASME boiler \& pressure vessel code Section III class 1 components, rules for construction of nuclear facility nuclear components, The America Society of Mechanical Engineers, July 1, 2007.

[11]. FRANK M. WHITE, Fluids Mechanics, fourth edition, McGraw Hill, Boston, United States, Page 45, 227-229, 1997.

[12]. PATRAN User's Guide - MSC Software, MSC Software Corporation, 2012. 